\title{
Unilateral congenital dysplasia of lung associated with vascular anomalies
}

\author{
ALISON HISLOP, M. SANDERSON, and LYNNE REID \\ Department of Experimental Pathology, Cardiothoracic Institute, Brompton Hospital, London S.W.3
}

\begin{abstract}
Hislop, A., Sanderson, M., and Reid, L. (1973). Thorax, 28, 435-441. Unilateral congenital dysplasia of lung associated with vascular anomalies. In three cases of unilateral lung dysplasia the structural changes have been analysed quantitatively to throw light on the nature of the anomaly and stage of its appearance. In one case the pulmonary artery was hypoplastic and the systemic supply normal but increased, suggesting onset in late intrauterine life or early childhood: in the other two cases the blood supply was only systemic, from both normal and abnormal arteries, suggesting onset in the early weeks of intrauterine development. Airway development was consistent with this interpretation. All cases had additional signs of maldevelopment of mesodermal tissue. The origin of the various types of systemic artery is discussed.
\end{abstract}

The first report of absence of one pulmonary artery arose from a chance necropsy finding (Fraentzel, 1868) and it was 46 years later that a second case was described (Doering, 1914). Diagnosis during life, by angiography, was reported by Madoff, Gaensler, and Strieder (1952). This condition seems to be relatively rare as by 1969 Ferguson, Bellean, and Gaensler found only 40 patients with this as the sole lesion: more commonly it is found with other congenital heart lesions (Steinberg, 1958).

Such lungs are supplied by systemic vessels, arising from either the ascending or descending aorta, and evidently anastomosing with pulmonary arteries within the lung. In other cases absence of the pulmonary venous drainage is described (Maier, 1954; Jones, 1955; Newman, Tarasidis, and Chai, 1964). In some reports it has been assumed that the vessels within the lung are normal and that a pulmonary vein is present (Anderson, Char, and Adams, 1958; Pool, Vogel, and Blount, 1962; Nordenström, 1963; Oakley, Glick, and McCredie, 1963; Ferguson et al., 1969). The possible embryological abnormality (Anderson et al., 1958; Pool et al., 1962) and the respiratory function of these lungs have been discussed (Pool et al., 1962; Oakley et al., 1963; Ferguson et al., 1969) but there has been little comment on the intrapulmonary lung structure. Maier (1954) described diffuse thickening of the alveolar walls in a patient with an absent right pulmonary artery. Anderson and Oakley and their associates commented only on the normal structure of the intrapulmonary vessels in the hypoplastic lung and changes in the media in those in the other. Newman et al. (1964) described, in a lung with absent pulmonary artery and vein, abnormal air spaces beyond terminal bronchioli associated with an increase in muscle in the parenchyma. In a second case they described fibrosed alveolar walls and 'hypoplastic muscle.'

The detailed macroscopic distribution of the blood vessels has been described only once (Tammeling, Nieveen, and Sluiter, 1967). In this case at necropsy all vascular systems were injected and no pulmonary artery was found, but there was a normal pulmonary venous return and, at the hilum, anastomoses between branches from the internal mammary artery and thinwalled pulmonary arteries that were distributed with airways. The bronchial arteries were not enlarged. Histologically the connective tissue septa were thickened by increase in lymphatics and bundles of smooth muscle and, in the walls of adjacent alveoli, collagen was increased.

As in each of the three cases reported here the systemic supply was greatly increased, it was thought appropriate to report them together. As far as was possible, depending on the condition of the specimen when received, the pattern and degree of development of the airways, arteries, and alveoli have each been assessed in the light of normal lung development (Hislop and Reid, 1973). 
T A B LE I

SUMMARY OF CLINICAL FINDINGS IN THREE CASES OF DYSPLASIA

\begin{tabular}{|c|c|c|c|}
\hline & $\begin{array}{l}\text { Case } 1 \\
\text { Female }\end{array}$ & $\underset{\text { Female }}{2}$ & $\begin{array}{l}\text { Case } 3 \\
\text { Female }\end{array}$ \\
\hline $\begin{array}{l}\text { Presenting symptom } \\
\text { Age at pneumonectomy } \\
\text { Findings in affected lung } \\
\text { Radiograph } \\
\text { Bronchogram } \\
\text { Angiogram } \\
\text { Bronchospirometry }\end{array}$ & $\begin{array}{l}\text { Recurrent respiratory infection } \\
\text { since childhood } \\
20 \text {-left } \\
\text { Lung small (Fig. 1) } \\
\text { Airways small } \\
\text { Arteries small }\end{array}$ & $\begin{array}{l}\text { Shortness of breath } \\
30 \text {-right } \\
\text { Lung small } \\
\text { Airways small and segmental } \\
\text { pattern abnormal (Fig. 3) } \\
\text { No right pulmonary artery. } \\
\text { Supply by bronchial +other } \\
\text { systemic vessels (Fig. 4) } \\
\text { Right lung: } \\
\text { Vital capacity } 0.31 \text {. } \\
\text { O uptake nil } \\
\text { Left lung: } \\
\text { Vital capacity } 1.11 \text {. }\end{array}$ & $\begin{array}{l}\text { Infection and purulent sputum } \\
\text { since birth } \\
\text { 22-right } \\
\text { Lung small and opaque } \\
\text { Abnormal hilar branching } \\
\text { No right pulmonary artery. } \\
\text { Supply from systemic arterie } \\
\text { above and below diaphragm }\end{array}$ \\
\hline
\end{tabular}

T A B L E I I

SUMMARY OF PATHOLOGICAL FINDINGS IN THREE CASES OF DYSPLASIA

\begin{tabular}{|c|c|c|c|c|}
\hline & Case 1 & Case 2 & Case 3 & Normal Adu \\
\hline $\begin{array}{l}\text { Lung volume (ml) } \\
\text { Adhesions } \\
\text { Pulmonary artery } \\
\text { Pulmonary vein } \\
\text { Bronchial artery } \\
\text { Other systemic arteries } \\
\text { Bronchial generations along axial pathway } \\
\text { Alveolar number } \\
\text { Alveoli/ml } \\
\text { Radial alveolar count } \\
\text { Alveolar surface area (one lung) }\end{array}$ & $\begin{array}{l}525 \\
\text { None } \\
\text { Hypoplastic } \\
\text { Hypoplastic } \\
\text { Enlarged } \\
\text { Absent } \\
22 \\
84 \times 10^{6} \\
170 \times 10^{3} \\
7 \cdot 1 \\
10 \cdot 8 \mathrm{~m}^{2}\end{array}$ & $\begin{array}{l}700 \\
\text { Localized } \\
\text { Absent } \\
\text { Hypoplastic } \\
\text { Enlarged } \\
\text { Supra and infra diaphragmatic } \\
11 \\
28 \times 10^{8} \\
133 \times 10^{3} \\
6.47 \\
-\end{array}$ & $\begin{array}{l}805 \\
\text { General } \\
\text { Absent } \\
\text { Absent } \\
\text { Enlarged } \\
\text { Infra diaphragmatic } \\
18 \\
42 \times 10^{6} \\
146 \times 10^{3} \\
= \\
-\end{array}$ & $\begin{array}{l}21-25^{2} \\
150 \times 10^{6} 1 \\
134 \times 10^{31} \\
9 \cdot 3^{3} \\
37 \cdot 5 \mathrm{~m}^{21}\end{array}$ \\
\hline
\end{tabular}

Mesodermal dysplasia

Case 1 Interlacing white bands in pleura (Fig. 2). Muscle in alveolar region. Additional abnormal vessels in bronchial walls, pleura, septa and vessel sheaths

Case 2 All vessels abnormal in position and with thick walls. Large tracts of fibrous and muscular tissue in alveolar region, bronchial walis, pleura, and septa

Case 3 All vessels abnormal in position and with very thick walls (up to $8 \%$ even after injection). Air-filled cysts occupy $20 \%$ of lung volumio (Fig. 5)

Dunnill (1962)

${ }^{2}$ Hayward and Reid (1952)

${ }^{3}$ Emery and Mithal (1960)

MATERIALS AND METHODS

The clinical features are presented (Table I). In case 1 the left lung was received fixed and inflated; from case 2 the right lung was received fixed with two vessel systems already injected, each with a different coloured gelatin solution: in case 3 the right lung was prepared for examination in our customary way by injecting the vessels with a barium sulphate/gelatin solution before inflating the lung with formol saline (Hislop and Reid, 1970).

Precise quantitative methods of analysis have been used to investigate the way in which growth of these lungs has been abnormal ; these included tracing airway and vessel branching, and estimation of alveolar size and number and assessment of muscularity of vessels, as described in a previous paper (Hislop and Reid, 1970). As two of these cases were received in a fixed state, complete analysis of the arteries was not possible. The pathological features are summarized in Table II.

\section{SUMMARY OF FINDINGS}

All three lungs were small in volume witb reduction in total alveolar number: alveola size was uneven through each lung, some alveo being small, others emphysematous: the average size in each lung was normal or reduced. IR case 1 , which had the highest alveolar count, the airways were normal in number but the alveoki were smallest. In both the other cases the airway? were reduced in number, suggesting a develope mental abnormality in the first half of intraథ uterine life-since all pre-acinar bronchiat branching is completed by 16 weeks' gestation (Bucher and Reid, 1961). In case 1 also, although the proximal pulmonary artery was reduced i size its distribution was normal. In the otheo cases there was neither a pulmonary arterE supply nor a normal pulmonary vein, the arteriad 


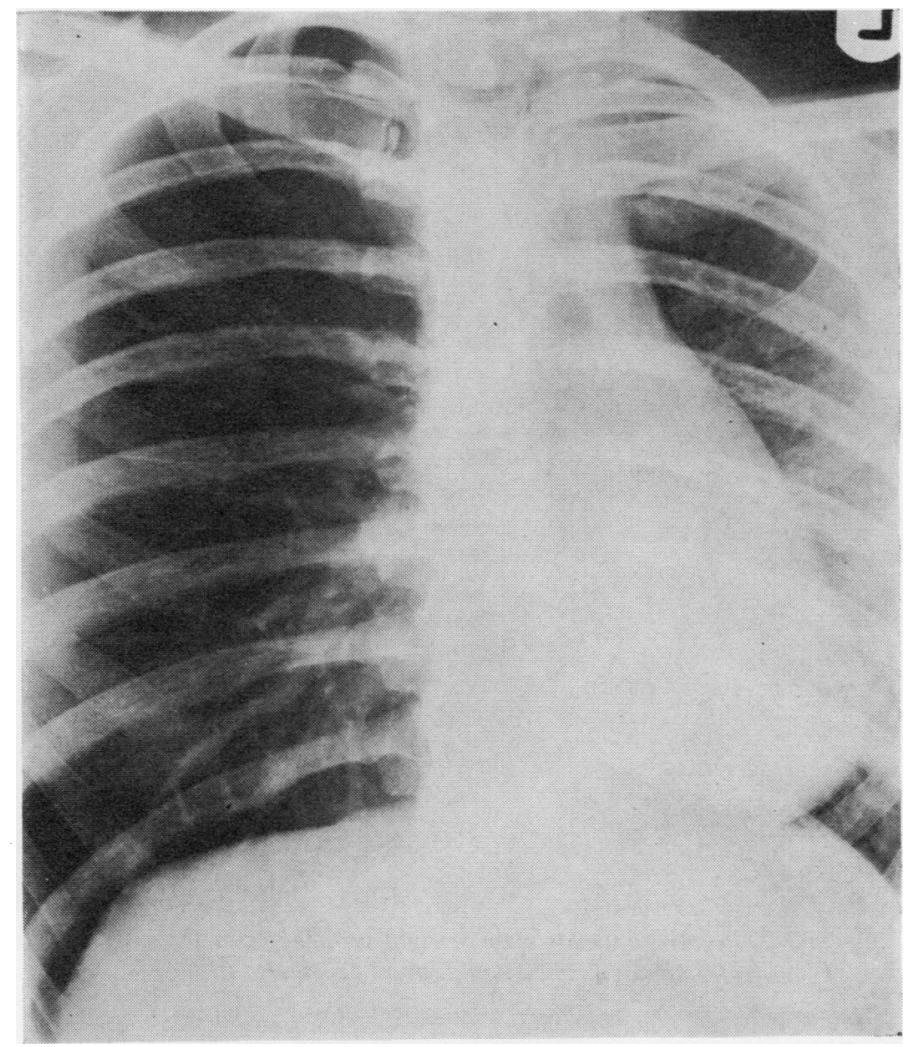

FIG. 1. Case 1. Postero-anterior radiograph showing small left lung.

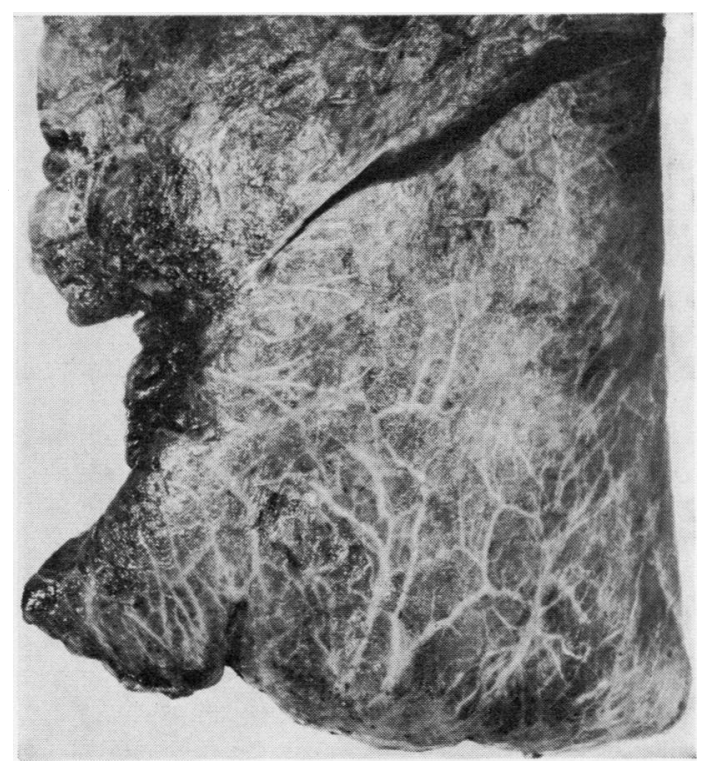

FIG. 2. Case 1. Lateral surface of left lung showing numerous interlacing white bands within the pleura. These were later shown to be muscle bundles, a few of which had a lumen. 

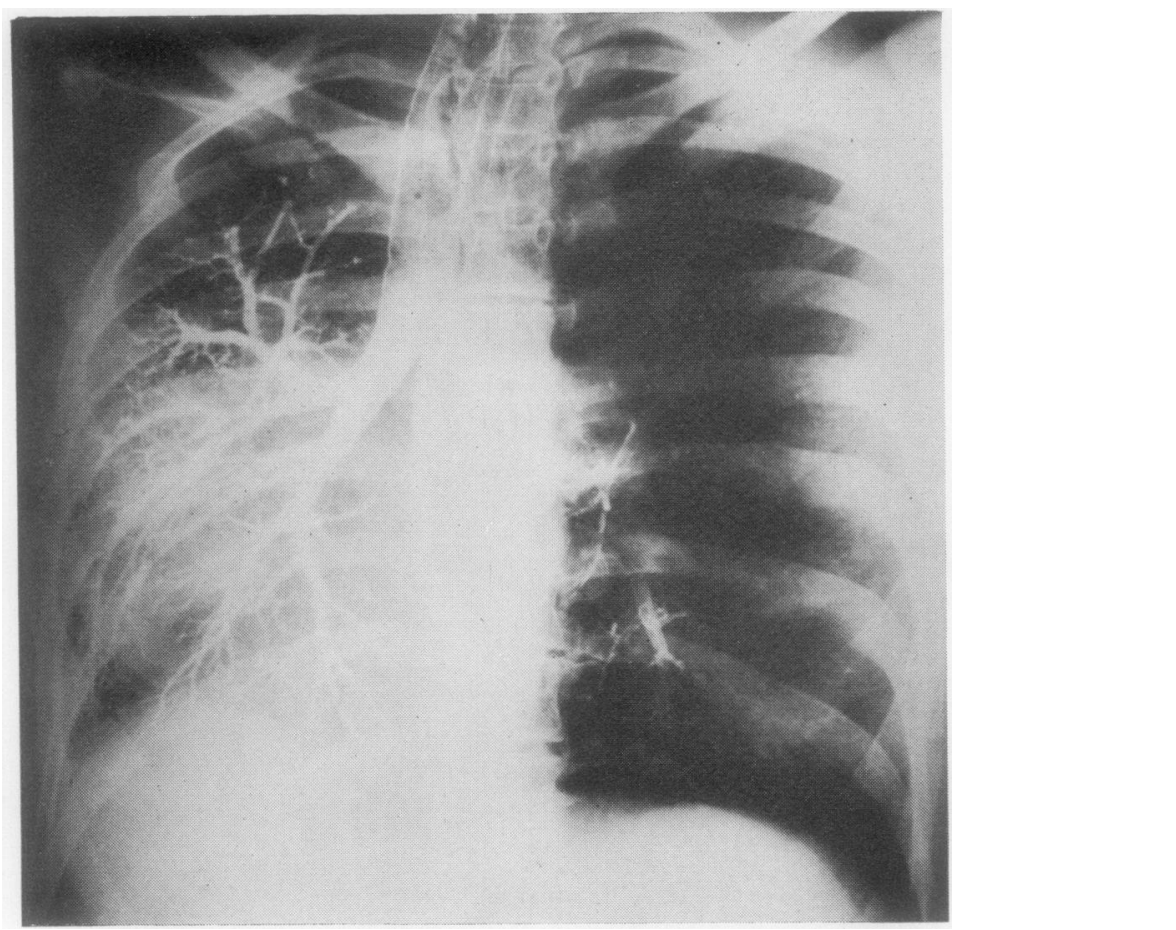

FIG. 3. Case 2. Postero-anterior view of right bronchogram showing abnormal pattern of segmental airway branching but good peripheral filling.

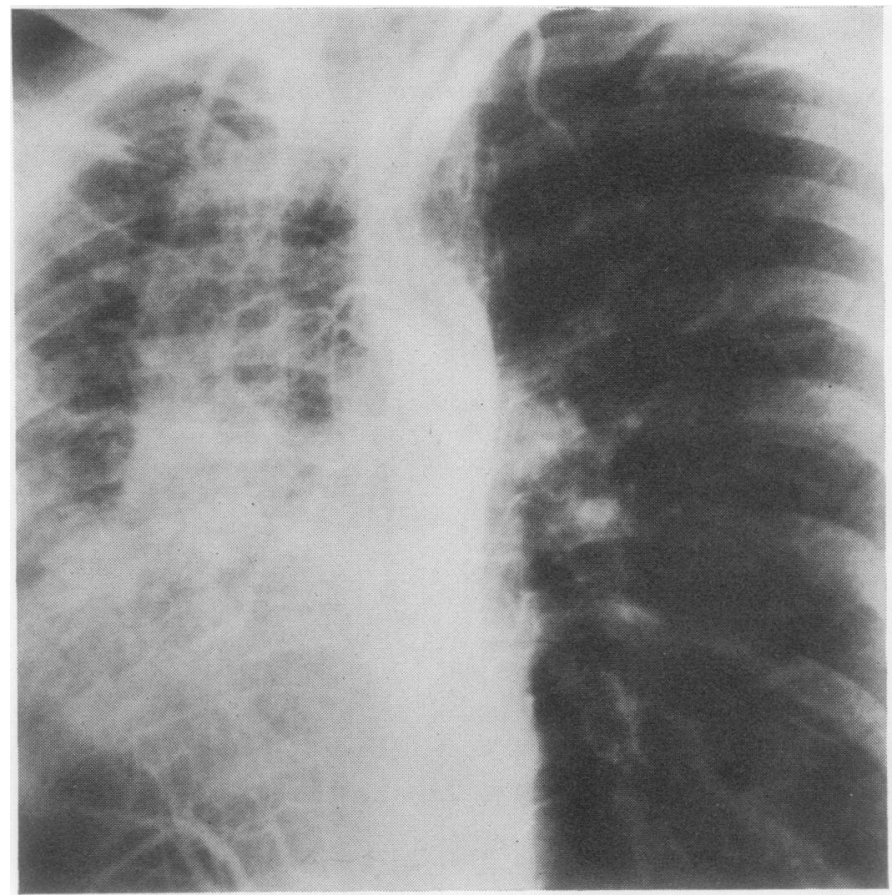

FIG. 4. Case 2. Aortogram showing that the right lung is supplied by systemic arteries from bronchial, intercostal, and subdiaphragmatic branches of the aorta. An earlier frame showed a small artery from the ascending aorta. 


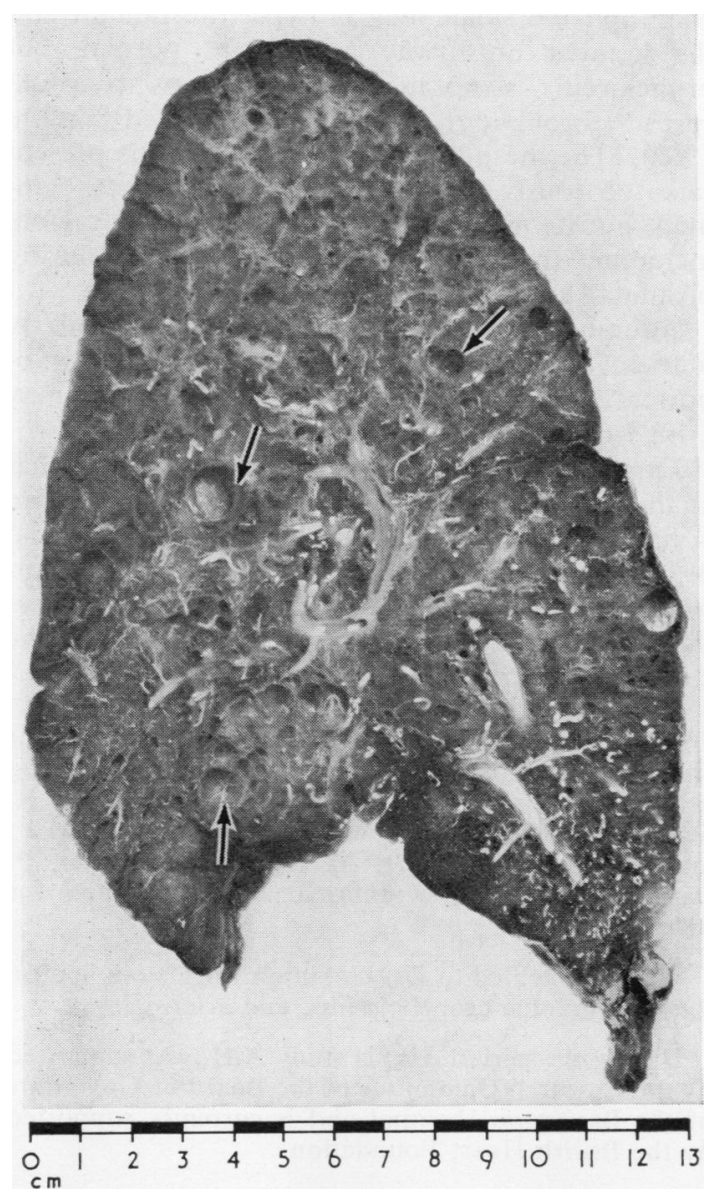

FIG. 5. Case 3. Slice of fixed right lung showing filled vessels (white). None was in the normal position of a pulmonary artery: they were in airway walls, connective tissue septa, lymph nodes, and running independently in the parenchyma. Air-filled cysts were found throughout the lung, up to $1 \mathrm{~cm}$ in diameter (arrows) microscopically lined by flattened epithelium or collagen and not seen to open into the airway. Connection with normal alveoli occasionally seen.

supply being from enlarged systemic vessels, either bronchial arteries or other supra and infra diaphragmatic aortic branches. All three cases showed some type of mesodermal dysplasiaabnormal vascular pathways, ectopic muscle, air-filled cysts.

Functionally the lung from case 1 would be performing gas transfer, even if less efficiently than in a normal lung, since the number of alveoli and hence alveolar surface area was reduced; the pulmonary artery and vein were also reduced in size. In addition, some pulmonary arteries accompanying small airways were obliterated, which would reduce the blood flow to the capillary bed. In cases 2 and 3 , as the lung received only oxygenated blood, no gas transfer would occur, the lungs being an extra organ in the systemic circulation. Bronchospirometric studies established this in case 2 . In a case reported by Oakley et al. (1963) with an absent left pulmonary artery there was only $9 \%$ oxygen uptake.

\section{DISCUSSION}

In all three cases described here there is mesodermal dysplasia, the main disturbance being in the blood vessel arrangement and in the abnormal distribution of muscle. This points to the condition being congenital; taking into account the size and position of the affected structure, it is possible to determine the antenatal stage at which these changes occurred.

The normal connections of the pulmonary artery to the heart are established by the fiftieth day of intrauterine development (Congdon, 1922). Heiss (1919) showed that the lobar and segmental airway pattern was laid down within 35 days. Reduction in the number of bronchial branches suggests abnormal growth before the sixteenth week of intrauterine development, by which time growth is normally complete (Bucher and Reid, 1961). In case 1 the airways and large vessels seem to have developed normally but with an excess of muscle bundles in the more peripheral part of the lung. This may represent a less severe anomaly or simply a later manifestation of the anomaly in the second half of intrauterine life. The alveolar number was equivalent to that of a 2-year-old child, although the alveoli were not too abnormal in size, indicating an anomalous development in early childhood. In the other two cases the branching pattern of both airways and vessels was affected close to the hilum, which suggests that both epithelium and mesoderm were affected in the developing lung and at an early stage. In case 3 in the peripheral part of the lung there were numerous cysts, suggesting that at least here some anomalous development occurred even after birth. It seems then that these changes, although they may start very early in intrauterine life, do also represent anomalous postnatal development, although the abnormal blood supply may contribute to the later anomalies.

In case 1 there was a hypoplastic pulmonary artery at the hilum; the peripheral intrapulmon- 
ary artery system was abnormal and augmented by a large bronchial artery. The normal connection of the hypoplastic pulmonary artery had not prevented an intrapulmonary abnormality. The lack of any normal pulmonary artery in cases 2 and 3 led to the development of a completely abnormal blood supply to the lung since in both cases it was supplied by vessels from the descending aorta. Before the development of the pulmonary artery the lung is supplied by small transitory branches of the dorsal aorta (Congdon, 1922) which disappear later, although they may persist if the pulmonary artery does not develop. These transitory vessels, if they persist, will descend with the coeliac axis and supply the lung from below the diaphragm (Boyden, 1970a). Others arising higher up the aorta may remain above the diaphragm. The true or definitive bronchial arteries develop from the descending aorta in the ninth to twelfth week of gestation, that is after the descent of the coeliac axis and late in development of the bronchial tree (Boyden, 1970b). In cases 2 and 3 both types of vessel probably developed normally, but transitory ones had persisted and were abnormally large to compensate for the absence of the pulmonary artery. It seems preferable to regard all aortic vessels as representing one or other type of bronchial artery rather than to accept Pool's (1962) suggestion that abnormal aortic vessels are the result of abnormality in position of the proximal end of the pulmonary artery in the truncus arteriosus during the first few weeks of fetal life. They suggested that as the truncus arteriosus twists and divides, the pulmonary artery would become attached to the aorta rather than to the pulmonary trunk.

In two of the cases, despite the absence of a normal pulmonary artery, the airways system had differentiated normally: this system received a relatively normal systemic blood supply. Only in the case with normal central connections with the heart were normal intrapulmonary arteries and veins present (case 1). In the other two cases normal airway branching had not imposed a normal vascular pattern.

Apart from abnormal blood vessels the main evidence of mesodermal dysplasia is seen in the presence of large tracts of muscle, some, even in case 1, associated with proximal arteries and airways, others running independently through the alveolar region. It seems certain that these changes are developmental since they do not resemble those found in conditions acquired in childhood as, for example, in Macleod's syndrome. In this condition the small lung is hypertransradiant and the number of airway generations normal, buf bronchiolitis stenosans and obliterans is wide- $\frac{-}{0}$ spread throughout the lung (Reid and Simon 1962). The mesodermal disturbance in the presento cases obviously starts during intrauterine develop $\frac{0}{0}$ ment but its manifestations in the alveolar region, including the air cysts, probably arise duringo postnatal growth.

Adhesions present in case 3 , but particularly marked in case 2 , may be the result of the abnormal entrance of the systemic supply or mayi arise from intrauterine inflammation.

Experimentally, Rudnick (1933) has shown that at the lung bud stage an investment of mesodermw is necessary for normal development of bronchialo branching. This suggests that an early and in-? trinsic abnormality of the mesoderm may affect $\vec{c}$ the development of epithelial structures, as in the cases described here.

We should like to thank Dr. R. Y. Keers, consultant chest physician, Shelton, Stoke-on-Trent, for sending us the specimen of case 1 ; Mr. D. Thomas and Dr. R. Seal, of Sully Hospital, Penarth, Glam., for case $2 ;$ and Dr. E. L. Reid, Dr. M. T. Casey, and Dr. P. Landrigan, of Halifax Infirmary, Nova Scotia, for $\frac{\mathscr{D}}{D}$ case 3.

We are indebted to Dr. G. Simon for his opinion on $\overline{\vec{B}}$ the radiographs, bronchograms, and arteriograms.

During the period of this study A.H. was supportedo by the Research Committee of the Board of Governors of the Brompton Hospital and is currently supported by the British Heart Foundation.

\section{REFERENCES}

Anderson, R. C., Char, F., and Adams, P. (1958). Proximal interruption of a pulmonary arch (absence of one pulmonary artery). Case report and a new embryologic interpretation. Diseases of the Chest, 34, 73.

Boyden, E. A. (1970a). The developing bronchial arteries in $\mathrm{a}$ 을 fetus of the twelfth week. American Journal of Anatomy, 129, 357.

(1970b). The time lag in the development of bronchiain arteries. Anatomical Record, 166, 611.

Bucher, U., and Reid, L. (1961). Development of the intrasegmental bronchial tree: the pattern of branching and development of cartilage at various stages of intraeo uterine life. Thorax, 16, 207.

Congdon, E. D. (1922). Transformation of the aortic-arch system during the development of the human embryo. 0 Contributions to Embryology (Carnegie Institution), 14, 47.

Doering, H. (1914). Angeborener Defekt der rechten $\mathbb{D}$ Lungenarterie. Studien zur Pathologie der Entwicklung, $\frac{\varrho}{\Phi}$ Jena, 2, 41.

Dunnill, M. S. (1962). Postnatal growth of the lung. Thorax $17,329$. 
Emery, J. L., and Mithal, A. (1960). The number of alveoli in the terminal respiratory unit of man during late intrauterine life and childhood. Archives of Diseases in Childhood, 35, 544.

Ferguson, A., Bellean, R., and Gaensler, E. A. (1969). Congenital absence of one pulmonary artery. Respiration, 26, 300.

Fraentzel, O. (1868). Ein Fall von abnormer Communication der Aorta mit der Arteria pulmonalis. Virchows Archiv für pathologische Anatomie und Physiologie und für klinische Medizin, 43, 420.

Hayward, J., and Reid, L. (1952). Observations on the anatomy of the intrasegmental bronchial tree. Thorax, 7, 89.

Heiss, R. (1919). Zur Entwicklung und Anatomie der menschlichen Lunge. Archiv fur Anatomie und Physiologie, Anatomische Abteil, p. 1.

Hislop, A., and Reid, L. (1970). New pathological findings in emphysema of childhood. 1. Polyalveolar lobe with emphysema. Thorax, 25, 682.

- and - (1973). Growth and development of the respiratory system. In Scientific Foundations of Paediatrics, edited by J. A. Davis, and J. Dobbing. Heinemann, London. (In press).

Jones, P. (1955). Developmental defects in the lungs. Thorax, 10, 205.

Madoff, I. M., Gaensler, E. A., and Strieder, J. W. (1952). Congenital absence of the right pulmonary artery. Diagnosis by angiocardiography with cardiorespiratory studies. New England Journal of Medicine, 247, 149.
Maier, H. C. (1954). Absence or hypoplasia of a pulmonary artery with anomalous systemic arteries to the lung. Journal of Thoracic Surgery, 28, 145.

Newman, R. W., Tarasidis, G., and Chai, H. C. (1964). Congenital absence or hypoplasia of pulmonary artery. Journal of Thoracic Surgery, 47, 740.

Nordenström, B. (1963). Methods of altering circulatory dynamics to improve roentgen examination of the cardiovascular system. American Journal of Roentgenology, 89, 233.

Oakley, C., Glick, G., and McCredie, R. M. (1963). Congenital absence of a pulmonary artery. American Journal of Medicine, 34, 264.

Pool, P. E., Vogel, J. H. K., and Blount, S. G. (1962). Congenital unilateral absence of a pulmonary artery. The importance of flow in pulmonary hypertension. American Journal of Cardiology, 10, 706.

Reid, L., and Simon, G. (1962). Unilateral lung transradiancy. Thorax, 17, 230.

Rudnick, D. (1933). Developmental capacities of the chick lung in chorioallantoic grafts. Journal of Experimental Zoology, 66, 125.

Steinberg, I. (1958). Congenital absence of a main branch of the pulmonary artery. American Journal of Medicine, 24, 559.

Tammeling, G. J., Nieveen, J., and Sluiter, H. J. (1967). Studies on anomalous collateral systemic-pulmonary circulation: report of four cases. Circulation, 35, 457. 